\title{
Understanding domestic fuel use practices in an urban township
}

\author{
Tebogo Sole and Claire Wagner \\ Department of Psychology, Faculty of Humanities, University of Pretoria, Pretoria, South Africa
}

\begin{abstract}
Due to a number of complex interactions between socio-economic, cultural and political factors some households consume a portfolio of energy sources such as electricity, coal, paraffin, gas and solar power. The aim of this paper is to incorporate a social construction of technology perspective to understand multiple fuel practices. Nine participants were purposefully selected from Soshanguve, an urban township in Pretoria, South Africa. Data were collected through individual in-depth interviews and narrative analysis was used to generate findings. Stories about multiple fuel use in the household showed that the practice is common and forms part of the participants' lifestyles. Social, cultural and political meanings of fuel use are identified in the narratives. Suggested interventions to optimise multiple fuel use in this context include additional technology such as solar power, collaborations with manufacturers to improve existing fuel types that are seen as potentially hazardous and leveraging women's knowledge and position in the household to formalise education about multiple fuels. The role of government in providing subsidies for alternative energies and reviewing accessibility to electricity was also highlighted by the participants. It demonstrates that policy makers should actively involve consumers in household energy system decisions through deliberative dialogue with communities.
\end{abstract}

Keywords: energy consumption, energy management, energy use behaviour, multiple fuel practices, narrative analysis, social construction of technology 


\section{Introduction}

Since the democratic government of South Africa assumed office in 1994 there has been improved access to basic services, including electricity, for citizens who previously did not have the same rights as the privileged white minority (Madubansi \& Shackleton, 2007). The National Electrification Programme (NEP) was introduced as part of government's energy policies to widen access to provide adequate and affordable energy services in urban and rural households (Davis, 1998). The primary energy supply in South Africa is electricity, which is provided by the country's main power supplier, Eskom. The state-owned enterprise is struggling to keep pace with the increasing demand of a growing (mostly urban) population as well as heavy industry and the mining sector that have become important cornerstones of the economy, providing many employment opportunities and contributing approximately $23 \%$ of South Africa's Gross Domestic Price (GDP) (Department of Mineral Resources (DMR), 2012). As the demand for electricity in South Africa continues to increase, Eskom's selling price has risen significantly in order to fund capital expansion to meet future demand (Ramayia, 2013). The pricing of electricity has become a critical topic in the national dialogue (DMR, 2012). The National Electricity Regulator of South Africa (NERSA) has approved a 9.4\% electricity hike for 2016/17 (Pretorius \& le Cordeur, 2016), well above the inflation rate of around $6 \%$.

Despite the national government's progress in universal access to free basic services, energy poverty is still prevalent in lower income urban areas. A 2012 residential survey about energy-related behaviour and perceptions in South Africa indicated that households in these areas tend to rely on multiple fuel sources in order to ensure that their day-to-day energy requirements are adequately met (DMR, 2012). Multiple fuel use, also known as fuel stacking (Heltberg, 2005), refers to the choice to use a combination of traditional solid fuels and 
modern non-solid fuels, a practice that results from a number of complex interactions between economic, social and cultural explanations in urban households (Masera, Saatkamp, \& Kammen, 2000; Van der Kroon, Brouwer, \& Beukering, 2013). Reasons that may shape the environment in which households make their decisions include household income, family size, high costs of electrical appliances, cultural preferences, taste, dependability of supply (fuel availability), cooking and consumption habits (Mekonnen \& Kohlin, 2009). Furthermore, the use of multiple fuels is not static; different sources of energy are adopted or dropped, increased or reduced in any period when factors pertaining to the household or the fuels themselves change (Chambwera, 2004). Fuel stacking also provides a sense of energy security because dependence on a single fuel can leave households vulnerable to price variations and unreliable services (Sepp, 2014).

The South African government has set a target for attaining universal access by 2025 , providing access to modern energy forms (i.e., electricity and other renewable energy sources) and excluding harmful energy sources (i.e., paraffin, candles, wood fuel etc.) (Sustainable Energy Africa, 2014). If households in developing countries such as South Africa rely on fuel stacking to meet their energy requirements as well as to sustain certain social and cultural practices, government initiatives to limit their fuel choices may not address these needs.

The aim of this paper is to understand the practice of using multiple fuels within the household in an urban township in South Africa from the perspective of the social construction of technology. This understanding may give policy makers in developing countries insight into how the provision of energy could be structured in certain urban contexts. 


\section{Social construction of technology (SCOT)}

The social construction of technology (SCOT) perspective originates from Pinch and Bijker's (1987) article, "The Social Construction of Facts and Artifacts: Or How the Sociology of Science and the Sociology of Technology Might Benefit Each Other" and is based on a social constructivist approach to the study of technology. It consists of four related components: interpretive flexibility, relevant social groups, closure mechanisms and the wider context. Interpretive flexibility suggests that technology design is an open process that can produce different outcomes depending on the social circumstances of development. In this agencycentered approach, relevant social groups (i.e. the consumer or user of the artefact) are the agents who assign meaning to and identify relevant problems with respect to the artefact. An artefact is an object or tool produced or shaped by humans with a view of subsequent use (it has a cultural and historical interest). After identifying problems, conflict will arise and the process will end with a solution (degree of stabilisation of the artefact) (Bijker, 1987). This is called the 'closure mechanism', where problems are redefined so that they no longer pose challenges to social groups. Lastly, the wider context refers to the broader socio-cultural and political milieu in which artefact development takes place.

This paper incorporates SCOT's multi-directional view of the developmental process of an artefact to understand multiple fuel use in the household context (see Figure 1). For the purpose of this study, 'artefact' can be referred to as multiple fuels (technology is the application of energy to household activities), where the relevant social group is women (as household energy managers, consumers and users) who identify problems related to the artefact. The solutions to the problems are derived from the social group's indigenous knowledge contribution. This knowledge has the potential to improve the use of an artefact. 


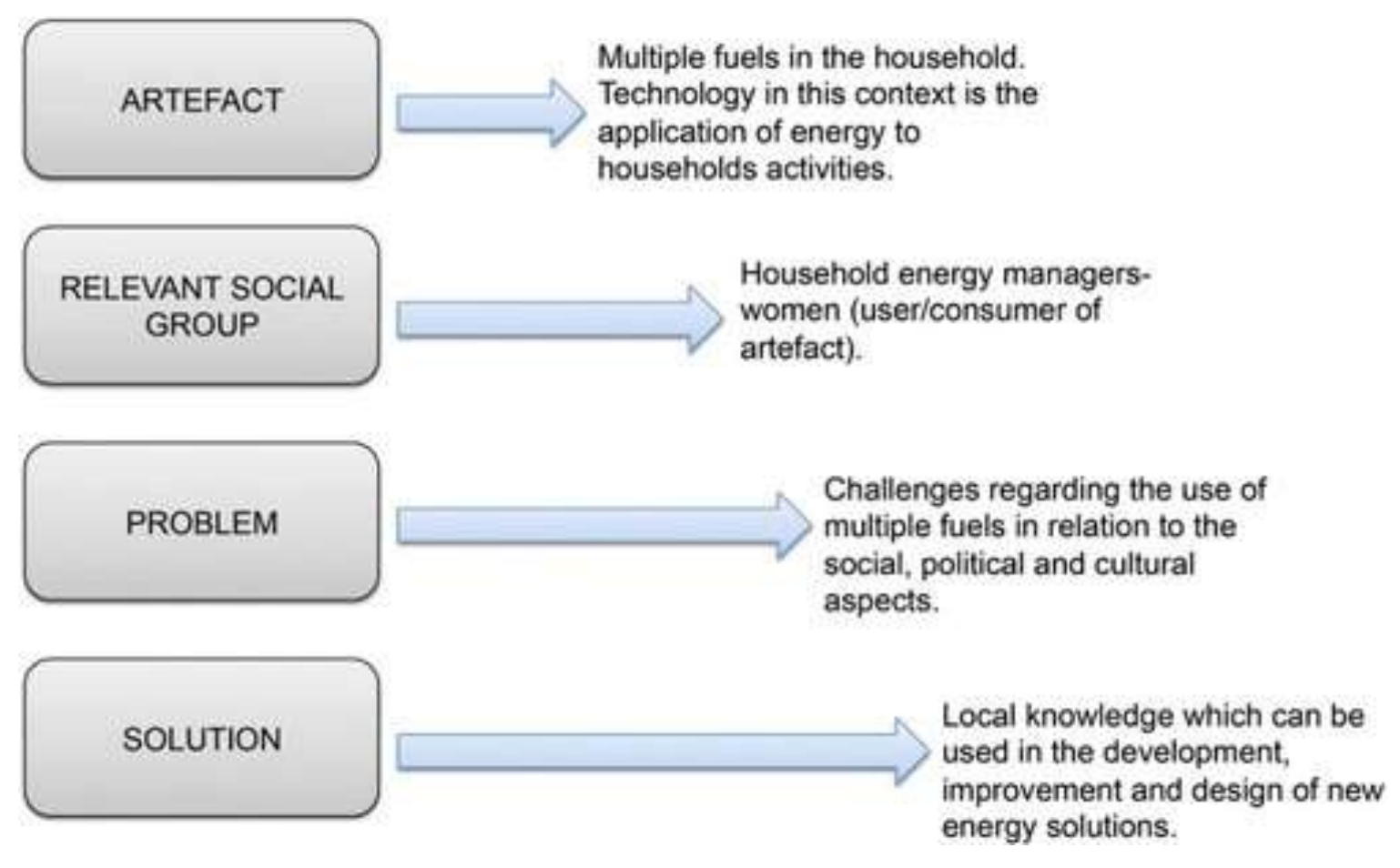

Figure 1. Social construction of technology's (SCOT) multidirectional view (of the developmental process of an artefact) to multiple fuel use in the household context.

Studies using SCOT indicate how multiple fuel practice is shaped by the user's socio-cultural and political situation, which in turn influences the choice of fuel (Mdluli \& Vogel, 2010; Naidoo \& Matlala, 2005). Private energy consumption is a result of a combination of activities, preferences, values, and technologies (Aune, 2007). Energy use within the household is not only technological, but also incorporates the user's social, political and cultural perspectives. Thus, energy in its own right provides little or no utility, but when used by people it can help fulfil a number of different household needs such as lighting, space heating and cooking. Users of energy in the household are not passive, but active agents who make smart fuel choices. Therefore, energy consumption has a symbolic meaning to the user. Multiple fuel practice highlights a significant relationship between the user and the technology itself - the two are intertwined (Olsson, 2015). 


\section{Research design and methods}

The two research questions for the study were:

1. How do participants choose various fuels within the household?

2. What are the meanings assigned to multiple fuel use by the participants (the social, political and cultural purposes these fuels serve in the household)?

The objective was to understand the social construction of technology using SCOT's four components (i.e. interpretive flexibility, relevant social groups, closure mechanisms and the wider context) and to obtain meaning(s) assigned to multiple fuel use by the participants.

To answer the research questions it was necessary to collect data in an area where households make use of multiple fuels. The first author lives in Soshanguve, an urban township in Pretoria in the northern part of the Gauteng Province, South Africa (see Figure 2 for images depicting typical households and energy sources). She has observed households in Soshanguve making use of various energy sources (e.g. electricity, solar power, wood, paraffin and gas). The area was therefore ideal to study multiple fuel practices.

In 2011 the population in Soshanguve was projected to stand at 403,162 consisting of 106,057 households. The township consists of both formal and informal areas with an average household size of 3.7. More than a third of households are headed by women (Statistics South Africa, 2011). Infrastructure development is said to be good with $90 \%$ of the population having access to electricity (Nkemngu, 2012). The area is, however, not immune to the increases in electricity pricing that are most notably felt by the poor and unemployed who largely experience energy poverty (Weakley, 2012). 
A SCOT approach commonly features concepts grounded in specific contexts where detailed, qualitative work is undertaken (Harty, 2006). Narrative inquiry was chosen for this study as a means to elicit stories from the participants about their household fuel use. As a method it enabled the researchers to understand how multiple energy sources are employed as the participants told stories of their daily household routines and practices. The transition of household energy use - due to improved access to basic services since 1994 - was also of interest and thus narrative enquiry's element of temporality (past, present and future) (Clandinin, 2007) was another key aspect of the study.

\section{Participants}

Household energy consumption studies tend to neglect the behaviour of energy users even though the user is central to understanding residential fuel choices and consumption patterns (Yuval \& Veturi, 2010). The acquisition of energy sources, management and use is a woman's responsibility by virtue of her traditional gender role (Balmer, 2007). Women remain at the centre of the family in most cases; evidence suggests that women do more housework and childcare than men even while they are in full-time employment (Erickson, 2005; Yapp, 2015). Thus, women are still responsible for the cooking in households and make critical decisions about fuel substitution and the purchase of stoves and other appliances, based on their fuel preferences and budget constraints. Comparative studies on women's fuel choices in urban areas indicate that women make decisions on fuel choices and use a variety of fuels in their households for various household activities (Mekonnen \& Kohlin, 2009; Rao \& Reddy, 2007). Research on the role of women in sustainable energy development shows that they provide valuable indigenous knowledge for new household energy technologies and projects. For example, rural women in South Asia contributed to improving the design of a wood stove by providing definitions of what a good quality stove 
meant - it should be smokeless, cook a variety of dishes as quickly as possible and consume less fuel than current stoves (Bloomfield, 2014). Women were thus chosen as participants in the current study as they are the main users and managers of household energy and have much to contribute to energy sustainability, but have been largely overlooked in the literature (Yuval \& Veturi, 2010).

A purposive method was used to select the study's participants. The predefined criteria that the target population had to meet to be included in the sample (Newig, 2011) entailed the following: the woman (18 years and older in the household identifying herself as the person responsible for managing its energy use); living in a brick house (brick houses represent a formal settlement in the area and also the house is energy efficient as it encompasses basic components of a passive solar design that has a high thermal mass (Klunne, 2002) and can influence the choices households make about heating); with a legal electricity supply (a common modern fuel expected to be readily available within the formal brick houses) from the local municipality; using prepaid electricity (households using prepaid electricity have the opportunity to monitor their electricity usage on a daily basis as they buy electricity as needed and do not have to wait for the municipality to inform them about their electricity usage at the end of the month ); living in a household consisting of two or more permanent residing members (excluding the participant; family size is one of many reasons that may shape the environment in which households make their decisions); using two or more energy fuels (multiple fuel use needed to be a deliberate choice, used in parallel and not as a back-up plan).

Potential participants were identified through the use of a social group (older women at the first author's church) to inquire about which houses utilised multiple fuels and fitted the 
study's criteria. The church members pointed out specific houses located in various sections of Soshanguve (i.e. Block BB, DD, F, P and the extensions). The first author went to the specified houses to recruit participants. If the appropriate member of the household was not available, the researcher moved on to the next specified house until a sufficient number of participants was recruited. Nine participants met the criteria and were included in the study. When the first author (interviewer) approached participants, she explained the purpose of the study to them and asked them to participate in the study. Once permission was granted by the participant and she had signed an informed consent form, a face-to-face interview took place at the participant's home on a date and time that best suited her.

\section{Data collection and analysis}

Literature from previous studies was used to develop the questions in the interview guide. Questions based on identified gaps in the knowledge about multiple fuel use were also incorporated. The following questions serve as examples of what the interview entailed: "Tell me about the roles and responsibilities of being a woman in Soshanguve"; "When did you first see the use of multiple fuels; "What type(s) of fuel do you currently use in your household?”; "Do you see yourself continue using multiple fuels in the future?". The interviews were conducted in the participant's preferred language (English, Sotho and Nguni languages spoken in the area and languages that the interviewer was fluent in). Each interview lasted for approximately 60 minutes. All interviews were tape-recorded, transcribed verbatim and translated into English.

A basic analysis of the socio-demographic characteristics of the sample was done to provide a description of the participants. Then, a narrative analysis of the interviews commenced in three phases: Firstly, a short descriptive summary of all the narratives and the key features 
such as the beginning (past), the middle (present) and the end (future) was generated. Secondly, each story was coded using a frame similar to that of thematic analysis using the first four steps from the six steps proposed by Braun and Clarke (2006). The social, cultural and political aspects of each story were grouped together in separate themes. Thirdly, an interpretative phase was entered into. This phase connects the narrative with the broader theoretical literature in order to interpret the story so that it goes beyond the descriptive phase to develop an interpretation of the stories.

\section{Findings}

\section{Demographic data}

The nine female participants' ages ranged from 32 to 69 years. Five of the nine participants were employed either on a full- time or part-time basis and the remaining four were unemployed. Only four participants had obtained a tertiary qualification. Three of the participants were the head of the household, three were the spouse of the head of the household and three were dependents in households. The various types of fuels they used in their households included wood, solar power, paraffin, gas, electricity and coal. All participants used electricity; paraffin and wood were also popular fuels. The least used fuels were solar energy and coal.

\section{Interpretive flexibility}

Interpretive flexibility is characterised in the current study by the availability of multiple fuels in the area the participants reside in. The availability of multiple fuels influences the selection of fuel use for various household activities. The participants understand that there are different levels of access to these fuels. Electricity is contained in the household infrastructure: 
It's ever ready, you do not need to go elsewhere to fill up or buy ... anytime you would want to use it is readily available, unlike wood, you will have to go out and look for them and then start the fire (Ms D).

Although wood is not as accessible as electricity it typically does not involve any costs to the participants because it is sourced from the trees in their backyards or in nearby fields: ' $W e$ don't buy wood as it's always available' (Ms L). It does, however, involve some labour to process: 'You have to chop it down first [the tree] and then break it into pieces, and then place it under the sun to dry out (Ms D)'.

One also needs to be knowledgeable about suitable trees to use for cooking, ones that do not create a wood aroma in the food such as the Moselesele (sickle bush), Mogonono/Mosusu (silver cluster leaf) and Mosehla (weeping wattle). Ms D learnt to differentiate between usable and non-usable types of trees when growing up in a rural area: '...if the tree itself smells, it will usually make your cooked food smell'. Ms T also knows that not all the trees are suitable to be used for cooking because 'some of them will create poison in the food'. She has experience in working with trees as a fuel for cooking and feels fairly confident that she can identify suitable trees in the veld (field) to use for cooking.

Paraffin is purchased at the local tuck shops (known as spaza shops). Gas was the least accessible to participants as they would need to travel to an industrial site further away to fill their cylinders: 'I fill up the gas cylinder at the industrial site; however, when the gas is finished I buy paraffin at the garage or the local tuck shops nearby' (Ms S). 


\section{Relevant social groups}

Participants, as consumers and users of multiple fuels, identified challenges with the availability of electricity. Electricity was only introduced to some of the participants when they moved from rural areas to Soshanguve. According to the participants, electricity was affordable in the past and the quantity of units they received then (from the municipality) was enough to sustain their household needs. Today the use of electricity poses various challenges such as the demand being high and heavy usage often leading to power outages, electricity units finishing quickly, and electricity being too expensive (especially for the unemployed). Ms M and Ms K both described how the amount of electricity units has changed over the years and this has prompted Ms $\mathrm{K}$ to use a paraffin stove or wood fuel in the household to save electricity:

When I started working and living here, electricity worth R100 it was about 300 and something units back then, now R100 electricity you won't even get 100 units, its 50 something or 60 something units (Ms M).

Electricity today is not the same as in the past...in terms of units [it is] minimised to become less. When I use electricity I feel like I am using it over I see it quickly finishing up and it is consuming time... Electricity lasts me longer when I use other fuels as well (Ms K).

Some of the households cannot afford enough electricity because of unemployment that is a contributing factor in energy poverty. In Ms B's case associations with alternative fuels, such as wood, are painful: 
Poverty pushed me into using multiple fuels. My heart bleeds when I think of using wood - going out to seek wood even when it was raining...you would be sick. In my case, it pains me especially when I have to do it again.

The lack of affordability of electricity will likely continue to be a problem for unemployed participants and so it is expected that they will continue to use other fuels to save electricity.

\section{Closure mechanisms}

The challenges of the availability of electricity have not deterred the participants from using it. Instead, they indicated various strategies they use to save electricity In the past the participants' mothers used fuels like wood and cow dung (which were freely available) in order to save fuels which they had to purchase or were temporarily unavailable (coal, paraffin and in some instances electricity). These skills were carried over to the participants and influence their current fuel use. Therefore, electricity is used for cooking light meals (i.e. rice, gravy, chicken feet etc.) that do not require much time to cook, and for essentials like lighting and appliances (i.e. television). Ms P describes her experience of using an electric stove to prepare traditional foods which require more time to cook and has made her opt to use paraffin and gas fuel instead:

You think about time and decide to switch it off quickly even when the food is not properly cooked the way you would want it to be [and you] end up looking and counting the hours it took to cook. [So] yes they will cook, but you must know that the electricity will also be finished (laughing). We are starting to run away from using electricity much in that context. 
Another strategy used by a participant is to limit the number of times that she cooks. When Ms O does cook she makes food last in different ways:

Making gravy to last you for two days; beetroot maybe for the whole week because you just can't cook every day. You end up using canned foods a lot... for example, say you cook rice, you will end up eating it with tinned fish because it does not require too much time to prepare.

The participants manage to lower household fuel consumption by making use of blankets and water bottles (instead of electric heaters) for heating, especially in winter. They also prefer using solar geysers, coal stoves, paraffin stoves and direct sunlight to heat water for bathing purposes. In summer Ms L's household puts 'water inside the bucket and place it outside to be heated up by the sunlight' and in winter they mostly use a paraffin stove to boil water for bathing. Ms $\mathrm{O}$ heats water using a hose pipe which she places on the lawn to be warmed up by sunlight: 'that hosepipe releases hot water when the tap is opened'.

The participants use education as another strategy to save electricity. They teach members of the household about the importance of using multiple fuels to reduce household electricity consumption through informing, encouraging and, in some instances, demonstrating the practice itself. For example, Ms O taught her children to make a wood fire during the school holidays: 'My children can make a wood fire themselves without supervision'. Using various strategies to save energy enables the participants to actively manage their household fuel and in the process reduce electricity consumption. They therefore indicated that they will continue using these strategies because they benefit their households. 
Although using multiple fuels is beneficial for households, the participants were also aware of the dangers associated with their use [i.e. coal that is poured into an mbaula (a brazier that contains the hot coal), paraffin and gas]. Indoor pollution was discussed, for example, the participants have heard accounts of the smoke emitted by the mbaula killing children who inhaled it and the smoke causing lung ailments:

Smoke from the stove used in the house will cause asthma (Ms D).

My younger child together with myself are asthmatic. Those other fuels block us...gas as well, but if you use it nicely that smell it's like it does not exist (Ms $\mathrm{K})$.

Furthermore, one of the participants recounted how she had survived after inhaling the smoke from an mbaula that was left burning inside the house where she had been sleeping. The participants complained about the smell that paraffin stove leaves in the house after having used it. Participants who use gas also expressed their fears of using the fuel because of stories they heard from other users that it is dangerous. Ms S said that although she is afraid of using gas, she has become used to it:

People will tell you that it will explode [gas] and stuff... I mean it's not safe. I constantly have those thoughts in mind and I check to see if the cylinder is tightly closed. Using one fuel alone [electricity] is strenuous and if we are unable to purchase it, we experience difficulties... my household has become dependent on using gas fuel... gas is used to cook and boil water. 
Participants have educated themselves on various safety measures they can use to minimise potential hazards when using various fuels: 'Whenever she uses paraffin stove inside the house, she normally opens the windows' (Ms D). When using gas stoves, the participants check for leakages and make sure that the valves are tightly closed. Gas 'just needs you to be careful that you have screwed properly those things, but its clean' (Ms O). Although the use of fossil fuels in the household environment can be dangerous the participants indicated that because they are educated about various safety measures to minimise the potential hazards they are likely to continue utilising these fuels.

\section{Wider context}

The participants' fuel choices and multiple fuel practices are not limited to the household itself, but incorporate broader socio-cultural and political contexts. Multiple fuel use development has meanings associated with each of these contexts.

\section{Social meanings of multiple fuel use}

The use of multiple fuels is a point of conversation and interaction between the participants and their neighbours. Ms L, Ms D, and Ms T discuss multiple fuels and solutions to high electricity prices with their neighbours (it's like news... it's our daily bread (Ms D)) and even share resources. For example, Ms L will ask her neighbours for wood when she sees them chopping down a tree and Ms D borrows her neighbour's three legged pot when she wants to cook with wood fuel. In addition to talking to her neighbour, Ms D also learned things about multiple fuel use while residing in Soshanguve: firstly, that she is not the only one using it and, secondly that it is a way of survival and coping especially when one cannot afford electricity. Ms D also assists her grandmother with making wood fires. 
Fuel preferences between men and women in the household was not described in detail as only three of the participants were married and some of the participants said they do not know whether men's fuel choices differed from theirs. In some cases the participants said that the men in the household simply go with what is used in the home. However, what was clear from those participants who were married was that they received help from their husbands in terms of managing household fuel use and purchasing pre-paid electricity. In the case of Ms K household fuel choice is a joint responsibility:

We are both responsible...we are sort of sharing the responsibilities. This is because we don't receive our salaries on the same date, hence I get paid on the 15 th while my husband on the 26th of every month...so say I buy some when I get paid, he will add on top of that once he gets paid as well.

Ms K's husband also bought their gas stove and installed it. He takes responsibility for filling the gas cylinder thus assuming the technical role in the household while Ms $\mathrm{K}$ is the user of the equipment. The participants still fulfil traditional gender roles, taking responsibility for household tasks: 'household duties remain the same as the past - like washing dishes, cleaning and doing laundry' (Ms P).

\section{Cultural meanings of multiple fuel use}

The use of multiple fuels was described by the participants as a way of life that is also part of their cultural heritage. The participants' current fuel use is informed by their earlier experiences; skills that were learned from using multiple fuels in the past are now transferred to the present and influence household fuel decision making. Wood fuel has a particular historical meaning for the participants as Ms K explains: 
...it's a way of practicing old ways of doing things and it is a cultural heritage that should be preserved. [It reminds me of] weddings, parties, funeral ceremonies at the villages...people coming together around the fire outside and taking turns to check the pots (to specifically stir the pap [maize dish]) while having conversations. This thing [burning wood] goes back to where we come from.

Wood fuel is also mostly used to cook traditional foods even today. Traditional foods like cows' feet, beans, samp and tripe require a low heat to cook and thus take some time to prepare. The food is prepared in a three legged pot, colloquially called a drievoet. As Ms P explains food prepared in this way is said to taste better than if it were cooked using electricity:

Once you cook using firewood, you will be satisfied with how the food will be cooked. [Maize meal (pap) is cooked with wood fuel because] it's delicious ... tastier than if one cooked it with electric stove ... indeed it tastes different ... it comes out nicely and you will eat it I tell you. Those who grew up in rural areas can be able to differentiate the taste difference on the pap which is cooked using firewood or on the electric stove.

The participants are likely to continue using wood fuel to cook traditional food. Not only does wood fuel save electricity, but it also contributes a unique taste to the food.

\section{Political meanings of multiple fuel use}

\section{Access to free basic electricity "POP"}

The participants mentioned that some households in the area benefit from the Free Basic Electricity (FBE) programme initiated by the government to alleviate energy poverty. The 
locals label it 'POP', meaning 'poorest of the poor'. Households in areas populated by shacks, households with members that are all unemployed or with no formal employment, and pensioners typically receive these free units (100 units per month as reported by the beneficiaries). Some of the participants felt that the units last for a reasonable time, while others argued that they were insufficient. They reported, however, that if they use the POP electricity together with other fuels it lasts longer as described by Ms S:

Electricity on its own it does not last, a lot of people are crying over that. When I buy R50 electricity units, it will only last us when used in conjunction with gas.

Some participants proposed that as part of the policy, government should re-evaluate whether the current free electricity provided is sufficient to meet the needs of the household. If it is not sufficient, they would like the government to increase the electricity units to meet basic needs and improve households' quality of life.

\section{Further assistance for alleviating energy poverty}

The participants suggested that the government has a potential role in assisting the community to address power supply issues by, for example, reducing the municipal rates and taxes, increasing the number of free electricity units and allowing Eskom to supply them directly with electricity. Ms K referred to the municipality as the 'middle man' who does not act in the interest of consumers: 'Because I have recently discovered that people who get their supply of electricity directly from Eskom do not pay more compared to us'.

In addition, the participants shared some of their perceptions regarding fluctuations of rates and taxes. They argued that they are paying too much and that the municipality might be cheating them. Ms P said: 'There is no truth there in the way we pay, sometimes the rent 
[municipal account] reflects $R 1500$ and sometimes almost R2000'. She had to query her account at the municipal offices in town where she settled the matter, but felt that if you do not fix it they will cheat you'.

Participants called on government to assist by 'making sure that not everything in the household is run by electricity ... because electricity is expensive and everything runs on electricity, that is why it does not last' (Ms S). Participants also requested assistance with installing solar geysers that can serve as a main source of water heating in the households: 'this will be a way of meeting us half way' (Ms K).

\section{Discussion}

Findings suggest that multiple fuel use remains an enduring feature of the energy usage in the households that participated in the study which is consistent with the consumption patterns of both electrified and non-electrified houses in South Africa (DMR, 2012). The participants have access to a variety of fuels, both modern commercial fuels and traditional fuels. Each fuel contributes towards addressing a household's needs and the participants have preferences with regards to which fuel to use for a specific household activity. This indicates user flexibility meaning that participants choose which type of fuel needs to be used for cooking, heating and lighting purposes. Furthermore, multiple fuel use is not fixed, but constantly interpreted in different ways by the participants especially when certain factors (i.e. fuel prices, fuel security and poverty) pertaining to the household or the fuels themselves change (Chambwera, 2004). The participants' stories illustrated how energy consumption patterns in the household are constantly negotiated and redefined. Household members and neighbours support each other and co-operate in using multiple fuels. The practice of using multiple fuels is likely to remain as it benefits households by lowering electricity consumption, providing a 
sense of energy security (reduced dependence on a single fuel); and allowing households to exercise fuel choices and ensuring that they meet their needs. The downside, however, is the association of multiple fuels (especially biomass and petroleum fuels) with health hazards and negative environmental impacts because of their carbon emissions.

The social group in this study (women who manage their household's energy use) shared the same set of meanings about some of the difficulties of using electricity: demand being high, heavy usage often leading to power outages, electricity units finishing quickly, and electricity being too expensive, especially for the unemployed. The participants, however, managed to overcome some of these challenges by employing local knowledge (strategies) in the choices they made, minimising harm when using various fuels and educating household members on energy efficiency. Further interventions to optimise the use of multiple fuels in this context are suggested:

- For heating, sunlight was seen by participants as a source of energy that is clean, free and readily available. Solar water heaters would contribute positively to the alleviation of energy poverty in these households through providing a constant source of heated water (Wlokas, 2011).

- The participants identified problems with the way that paraffin and gas is used in households. Although some strategies are in place to cope with the situation (i.e. using the paraffin stove outside or opening windows when used inside and checking valves on gas stoves for leakages, the difficulties experienced with stoves using these fuels suggest that the manufacturers of these products could improve their functionality and usability and tailor them according to the users' needs or preferences (Peine \& Herrmann, 2012). Examples include designing safer paraffin stoves that will emit less smoke and making the stove more suitable to use inside the house, building in 
automatic leakage detectors in gas appliances and/or installing the gas cylinder component outside. Improving the design of gas stoves could minimize users' fears because the technology will have safety features that address their concerns.

- The participants were at the forefront of educating household members to save energy. This is consistent with findings from other studies that the operational duty for the use of energy fuel and education in the household is mostly left in the hands of the women (Mohammed \& Oyeniyl, 2012) while the involvement of men is felt more when decisions are required for the supply of energy (Roehr, 2002). This makes women essential role-players in enforcing rules and influencing energy efficient behaviours amongst other household members. Women's knowledge about multiple fuel use could be leveraged more efficiently and their positions as educators in the household used in a more formal way by disseminating information to policy makers and forming collaborations with role-players in the energy sector.

Using electricity saving strategies, or closure mechanisms, has enabled the participants to redefine the lack of availability of electricity as an opportunity to use their indigenous knowledge to allow their households to function. Understanding multiple fuel use requires the inclusion of a wider context (the broader socio-cultural and political environment) where the practice itself takes place. Socially, the practice of using multiple fuels is understood as a way of survival and coping with electricity increases, for example, when the participants discuss their fuel use with their neighbours and offer practical support (i.e. sharing wood fuel and drievoet cooking pots). Culturally, the practice is a way of life that is tied to the participants' heritage. The preference for cooking traditional foods using wood fuel illustrates their need to continue with this practice. From a political perspective the study highlighted the need for government to intervene to alleviate energy poverty and to support the 
community in addressing energy supply issues. This would include evaluating some of its existing energy interventions, for example, whether 100 units of free electricity is sufficient to meet household needs. The participants are open to the idea of installing solar geysers, provided the government meets them half way with subsidies, a mechanism that is regularly used to convince homeowners to invest in energy-efficient heating technologies (Aune, 2007). The participants' perceptions about electricity purchasing prices from the municipalities compared to buying directly from Eskom also need to be addressed.

\section{Conclusion and recommendations}

This paper incorporated the social construction of technology perspective to understand multiple fuel use practices in an urban township in South Africa. The findings highlighted SCOT's related components: interpretive flexibility, relevant social groups, closure mechanisms and the wider context, how they interact together and explain the importance of smart fuel choices women make through utilising multiple fuels. The participants' active involvement with household fuel choices enabled them to identify the gaps with the current energy (i.e. technology) and to suggest future solutions. They give meaning to the energy that is being utilised - technology in this regard is subject to interpretive flexibility and is a social process. The meanings originate from their socio-cultural and historical contexts. Therefore, there is a need for energy users to be involved in the technological development process as it takes place under specific local, social and historical contexts. In conclusion, knowledge about people's motives, needs, preferences and tastes is important in order to tailor information and influence the domestication of energy-efficient technology.

As the study made use of a small sample and a specific area of Soshanguve the participants may not be representative of all urban townships and the findings cannot be generalised 
outside this context. Qualitative research is not concerned with generalizability, but is vested in acquiring rich and detailed information about people's experiences (Willig, 2008). As such the study's findings can potentially be generalised in certain ways to other similar contexts. The use of a small sample also introduces bias in the data in that the participants' multiple fuel practices may not represent those of the rest of the community. The findings from this study open the door for future researchers to investigate the topic on a larger scale, using quantitative methods and random sampling to gather more representative evidence of people's fuel needs and practices in developing countries.

The findings from this study should also be of interest to researchers and policy makers either working in South Africa or other developing countries, or hoping to work in such countries. For researchers, this study indicates the importance of utilising qualitative research to explore and understand multiple fuel use practice. Multiple fuel use is context specific and influenced by various factors which researchers need to account for. Policy makers should actively involve consumers/users in energy system decisions through deliberative dialogue with communities (preferably the household energy managers). Consumer involvement plays a vital role for energy efficient technologies to be accepted and the process indirectly influences a positive energy consumption habit. Policies should aim at supporting and reinforcing existing technologies; in this context it would mean investing in future household developments that have built-in alternative fuels like solar water heaters and gas stoves. Household energy policy measures that support the use of renewable energy through providing subsidies and ensuring that they are reliable and affordable to home owners will help reduce dependency on one source of fuel (electricity) and secure more sustainable energy services that are aligned with people's social and cultural needs. 
It is recommended that more studies on multiple fuel use within urban areas pay attention to the role that women play in household energy use and how their stories can be used in developing alternative energy strategies. Although the ICT sector in South Africa is growing rapidly, the target of affordable access to the full range of communication services has not been met (Gillwald, Moyo, \& Stork, 2012). The participants in the current study spoke about energy meeting their basic needs; however, it is possible that ICT has increased electricity use in these households. Changes in technology in developing countries and issues around its energy use would be another interesting avenue for future research.

\section{Acknowledgement}

This study was funded by the National Research Foundation (NRF - Innovation category).

This paper is based on the research conducted for a Master's dissertation completed in 2016.

\section{References}

Aune, M. (2007). Energy comes home. Elsevier Energy Policy, 35(11), 5457-5465. doi: 10.1016/j.enpol.2007.05.007

Balmer, M. (2007). Energy poverty and cooking requirements: The forgotten issue in South African energy policy. Journal of Energy in Southern Africa, 18(3), 4-9. Retrieved from http://www.erc.uct.ac.za/jesa/volume18/18-3jesa-balmer.pdf

Bijker, W. (1987). The social construction of bakelite: Toward a theory of invention. In W. Bijker, T. Hughes, \& T. Pinch, The social construction of technological systems: New directions in the sociology and history of technology (pp. 17-50). Cambridge: MIT Press. 
Bloomfield, E. (2014). Gender and livelihoods impacts of clean cookstoves in South Asia. UK: Practical Action Consulting. Retrieved from https://cleancookstoves.org/binarydata/RESOURCE/file/000/000/363-1.pdf

Braun, V., \& Clarke, V. (2006). Using thematic analysis in psychology. Qualitative Research in Psychology, 3(2), 77-101. doi:10.1191/1478088706qp063oa

Chambwera, M. (2004). Economic analysis of urban fuelwood demand: The case of Harare in Zimbabwe (Doctoral dissertation). Retrieved from http://agris.fao.org/agrissearch/search.do?recordID=NL2005731381

Clandinin, D. J. (2007). Handbook of narrative inquiry: Mapping a methodology. California: Sage Publications.

Davis, M. (1998). Rural household energy consumption: The effects of access to electricityevidence from South Africa. Energy Policy, 26(3), 207-217. doi:10.1016/S03014215(97)00100-6

Department of Mineral Resources (DMR). (2012). A survey of energy-related behaviour and perceptions in South Africa: The residential sector. Retrieved from http://www.energy.gov.za/files/media/Pub/Survey\%20of\%20Energy\%20related\%20b ehaviour\%20and\%20perception\%20in\%20SA\%20-\%20Residential\%20Sector\%20$\% 202012 . p d f$

Erickson, R. J. (2005). Why emotion work matters: Sex, gender, and the division of household labour. Journal of Marriage and Family, 67(2), 337-351. doi: 10.1111/j.0022-2445.2005.00120.x

Gillwald, A., Moyo, M., \& Stork, C. (2012). What is happening in ICT in South Africa. A supply- and demand-side analysis of the ICT sector. Retrieved from http://www.researchictafrica.net/publications/Evidence_for_ICT_Policy_Action/Polic y_Paper_7_-_Understanding_what_is_happening_in_ICT_in_South_Africa.pdf 
Harty, C. (2005). Innovation in construction: A sociology of technology approach. Building Research and Information, 33(6), 512-522.

Heltberg, R. (2005). Factors determining household fuel choice in Guatamala. Environment and Development Economics, 10(1), 337-361. doi:10.1017/S1355770X04001858

Klunne, W. E. (2002). Energy efficient housing to benefit South African households. Boiling Point, 48(1), 27-29. Retrieved from http://practicalaction.org/boilingpoint/docs/energy/docs48/bp48_pp27-29.pdf

Madubansi, M., \& Shackleton, C. (2007). Changes in fuelwood use and selection following electrification in Bushbuckridge lowveld, South Africa. Journal of Environmental Management, 83 (1), 416-426. doi:10.1016/j.jenvman.2006.03.014

Masera, O. R., Saatkamp, B. D., \& Kammen, D. M. (2000). From linear fuel switching to multiple cooking strategies: A critique and alternative to the energy ladder model. World Development, 28(1), 2083-2103.

Mdluli, T. N., \& Vogel, C. H. (2010). Challenges to achieving a successful transition to a low carbon economy in South Africa: Examples from poor urban communities. Springer, 15, 205-222. doi: 10.1007/s11027-009-9195-4

Mekonnen, A., \& Kohlin, G. (2009). Determinants of household fuel choice in major cities in Ethiopia. Unpublished manuscript, School of Business, Economic and Law, University of Gothenburg, Gothenburg, Sweden. Retrieved from http://www.rff.org/RFF/Documents/EfD-DP-08-18.pdf

Mohammed, N., \& Oyeniyl, B. (2012). Role of rural women in household energy management in Tofa L.G.A of Kano State. Academic Research International, 3(3), 417-425. Retrieved from http://www.savap.org.pk/journals/ARInt./Vol.3 (3)/2012(3.3-48).pdf 
Naidoo, R., \& Matlala, M. E. (2005, September). Residential energy savings through multiple-fuel use and energy efficient appliances. Paper presented at the World Congress in Housing - Transforming Housing Environments through Design, Pretoria, South Africa. Retrieved from http://repository.up.ac.za/bitstream/handle/2263/10444/Residential\%20Energy\%20Sa vings\%20Through\%20Multi-Fuel\%20Use\%20and\%20Energy.pdf?sequence=1

Newig, H. (2011). Conducting research in conservation: A social science perspective. London: Routledge Publishers.

Nkemngu, P. (2012). Community benefit from tourism: Myth or reality a case study of the Soshanguve township. Journal of Tourism Hospitality, 1(5), 1-6. Retrieved from http://www.omicsgroup.org/journals/2167-0269/2167-0269-1-105.pdf

Olsson, L. (2015). Sociotechnical studies of the reduction of greenhouse gas emissions from energy and transport systems. (Doctoral dissertation). Retrieved from http://liu.divaportal.org/smash/get/diva2:799868/FULLTEXT01.pdf

Peine, A., \& Herrmann, A. M. (2012). The sources of use knowledge: Towards integrating the dynamics of technology use and design in the articulation of societal challenges. Technological Forecasting and Social Change, 79(1), 1495-1512. doi: 10.1016/j.techfore.2012.04.014

Pinch, T., \& Bijker, W. (1987). The social construction of facts and artefacts: Or how the sociology of science and the sociology of technology benefit each other. Social Studies of Science, 14(3), 399-441. doi: 10.1177/030631284014003004

Pretorius, W., \& le Cordeur, M. (2016, March 01). Nersa approves 9.4\% electricity price hike. Fin24. Retrieved from http://www.fin24.com/Economy/nersa-approves-94electricity-price-hike-20160301 
Ramayia, J. (2013, March 7). NERSA allows yearly 8\% electricity price increase for 20132018. Urban Earth. Retrieved from http://urbanearth.co.za/articles/nersa-allowsyearly-8-electricity-price-increase-2013-2018

Rao, M. N., \& Reddy, B. S. (2007). Variations in energy use by Indian households: An analysis of micro level data. Energy, 32(2), 143-153. doi:10.1016/j.energy.2006.03.012

Roehr, U. (2002, December). Differences and similarities (in gender and energy): A northsouth comparative analysis. Energia News. Retrieved from http://energia.org/wp-content/uploads/2014/11/en-2002-12.pdf

Sepp, S. (2014). Multiple household fuel use: A balanced choice between firewood, charcoal and LPG. Retrieved from https://cleancookstoves.org/binarydata/RESOURCE/file/000/000/287-1.pdf

Statistics South Africa. (2011). Census 2011: Metropolitan municipal statistic. Retrieved from http://www.statssa.gov.za/?page_id=4286\&id=11352

Sustainable Energy Africa. (2014). A shortened booklet version of the full report on tackling urban energy poverty in South Africa. Retrieved from http://www.sustainable.org.za/uploads/files/file72.pdf

Van der Kroon, B., Brouwer, R., \& Van Beukering, P. J. (2013). The energy ladder: Theoretical myth or empirical truth? Results from a meta-analysis. Renewable and Sustainable Energy Reviews, 20, 504-513. doi:10.1016/j.rser.2012.11.045

Weakley, D. (2012). Kya sands informal settlement: Vulnerability and resilience. In L. Poulsen, \& M. Silverman (Eds.), The South African informal city (pp. 49-54). Johannesburg: Architects' Collective. 
Willig, C. (2008). Introducing qualitative research in psychology (2nd ed.). Buckingham: Open University Press.

Wlokas, H. L. (2011). What contribution does the installation of solar water heaters make towards the alleviation of energy poverty in South Africa? Journal of Energy in Southern Africa, 2(22), 27-39. Retrieved from http://www.erc.uct.ac.za/jesa/volume22/22-2jesa-wlokas.pdf

Yapp, R. (2015, October 28). Working women 'still do housework'. Daily Mail Online. Retrieved from http://www.dailymail.co.uk/news/article-206381/Working-womenhousework.html

Yuval, F., \& Veturi, A. (2010). Questioning women's role in energy development. Retrieved from http://www.efonet.org 